\title{
Correspondence
}

\section{A survey of the treatment and management of patients with severe chronic spontaneous urticaria}

\author{
doi: $10.1111 /$ ced.13778
}

Chronic spontaneous urticaria (CSU) is characterized by the recurrent appearance of weals, angio-oedema or both, occurring at least twice weekly for longer than 6 weeks. ${ }^{1}$ It is often managed with antihistamines, but occasionally requires other systemic agents in recalcitrant cases.

A cross-sectional survey was conducted by means of an internet-based survey tool (Typeform; https://www. typeform.com). Participating consultants with a specialist interest in urticaria were identified through the specialist registers of the British Society of Allergy and Clinical Immunology (BSACI), the Improving Quality in Allergy Services (IQAS) Group and the British Association of Dermatologists (BAD), and invited to take part.

The survey content was based on current CSU treatment guidelines from EAACI/GA2LEN/EDF/WAO ${ }^{1}$ and the British Society for Allergy and Clinical Immunology (BSACI). ${ }^{2}$ The EAACI/GA2LEN/EDF/WAO guidelines are a joint initiative of the Dermatology Section of the European Academy of Allergy and Clinical Immunology (EAACI), the Global Allergy and Asthma European Network (GA2LEN) (a European Union-funded network of excellence), the European Dermatology Forum (EDF), and the World Allergy Organization (WAO). To standardize responses, all participants were presented with a case of recalcitrant CSU (failed on maximum dose of nonsedating antihistamines and montelukast), requiring alternative systemic treatment. Questions covered usage of systemic treatments, routine disease severity assessments, adherence to treatment guidelines and perceived barriers to prescribing.

Responses (Table 1) were received from 19 UK consultants (26 surveys sent; completion rate 73\%), 15 of whom had > 10 years' experience in the treatment of CSU. The majority were allergy (58\%) and dermatology consultants $(37 \%)$. Of the 19 consultants, $56 \%$ provide a dedicated urticaria service, $37 \%$ treat both adult and paediatric patients, and the majority $(79 \%)$ use systemic medications other than antihistamines and montelukast. Omalizumab and ciclosporin were the most commonly used first-line agents (47\% and 27\% respectively) (Fig. 1). The majority $(84 \%)$ of consultants use validated measures to assess disease severity, including the weekly Urticaria
Table 1 Summary of survey results.

\begin{tabular}{|c|c|}
\hline Parameter & Response, \% (n) \\
\hline \multicolumn{2}{|l|}{ Section 1: Demographics } \\
\hline \multicolumn{2}{|l|}{ Country of work } \\
\hline United Kingdom & $100 \%(19)$ \\
\hline \multicolumn{2}{|l|}{ Hospital grade } \\
\hline Consultant & $100 \%(19)$ \\
\hline \multicolumn{2}{|l|}{ Specialty } \\
\hline Allergy & $58 \%(11)$ \\
\hline Dermatology & $37 \%(7)$ \\
\hline Immunology & $5 \%(1)$ \\
\hline \multicolumn{2}{|l|}{ Caseload } \\
\hline Adult only & $42 \%(8)$ \\
\hline Both adult and paediatric & $37 \%(7)$ \\
\hline Paediatric only & $21 \%(4)$ \\
\hline \multicolumn{2}{|l|}{ Number of years in specialty } \\
\hline$>20$ & $53 \%(10)$ \\
\hline $10-20$ & $26 \%(5)$ \\
\hline$<10$ & $21 \%(4)$ \\
\hline \multicolumn{2}{|c|}{ Section 2: Use of systemic medications } \\
\hline \multicolumn{2}{|c|}{$\begin{array}{l}\text { Do you use systemic medication for the management of chronic } \\
\text { urticaria? }\end{array}$} \\
\hline Yes & $79 \%(15)$ \\
\hline No & $21 \%(4)$ \\
\hline \multicolumn{2}{|l|}{ First-line treatments? } \\
\hline Omalizumab & $47 \%(7)$ \\
\hline Ciclosporin & $28 \%(4)$ \\
\hline Other & $20 \%(3)$ \\
\hline Dapsone & $7 \%(1)$ \\
\hline \multicolumn{2}{|l|}{ Second-line treatments? } \\
\hline Omalizumab & $40 \%(6)$ \\
\hline Ciclosporin & $33 \%(5)$ \\
\hline Mycophenolate mofetil & $13 \%(2)$ \\
\hline Other & $13 \%(2)$ \\
\hline \multicolumn{2}{|l|}{ Third-line treatments? } \\
\hline Other & $27 \%(4)$ \\
\hline Dapsone & $20 \%(3)$ \\
\hline Ciclosporin & $13 \%(2)$ \\
\hline Methotrexate & $13 \%(2)$ \\
\hline Mycophenolate mofetil & $13 \%(2)$ \\
\hline \multicolumn{2}{|c|}{$\begin{array}{l}\text { If you use any of the listed } \\
\text { treatments in children, which ones do you use? }\end{array}$} \\
\hline Ciclosporin & $80 \%(4)$ \\
\hline Omalizumab & $80 \%(4)$ \\
\hline Azathioprine & $60 \%(3)$ \\
\hline Dapsone & $60 \%(3)$ \\
\hline Mycophenolate mofetil & $60 \%(3)$ \\
\hline Methotrexate & $20 \%(1)$ \\
\hline \multicolumn{2}{|c|}{ Section 3: Use of standardized measures } \\
\hline \multicolumn{2}{|c|}{$\begin{array}{l}\text { Do you use standardized } \\
\text { measures when assessing disease? }\end{array}$} \\
\hline Yes & $84 \%(16)$ \\
\hline No & $16 \%(3)$ \\
\hline
\end{tabular}


Table 1. continued

\begin{tabular}{|c|c|}
\hline Parameter & Response, \% ( $n$ \\
\hline \multicolumn{2}{|l|}{ Physician Global Assessment } \\
\hline Most of the time & $63 \%(10)$ \\
\hline Sometimes & $13 \%(2)$ \\
\hline Never & $25 \%(4)$ \\
\hline \multicolumn{2}{|l|}{ Patient Global Assessment } \\
\hline Most of the time & $44 \%(7)$ \\
\hline Sometimes & $25 \%(4)$ \\
\hline Rarely & $6 \%(1)$ \\
\hline Never & $25 \%(4)$ \\
\hline \multicolumn{2}{|l|}{ UAS-7 } \\
\hline Most of the time & $63 \%(10)$ \\
\hline Sometimes & $38 \%(6)$ \\
\hline \multicolumn{2}{|l|}{ In-clinic UAS } \\
\hline Most of the time & $25 \%(4)$ \\
\hline Sometimes & $13 \%(2)$ \\
\hline Rarely & $19 \%(3)$ \\
\hline Never & $44 \%(7)$ \\
\hline \multicolumn{2}{|l|}{ Angio-oedema Activity Score } \\
\hline Sometimes & $44 \%(7)$ \\
\hline Rarely & $25 \%(4)$ \\
\hline Never & $31 \%(5)$ \\
\hline \multicolumn{2}{|l|}{ Itch severity score } \\
\hline Most of the time & $13 \%(2)$ \\
\hline Sometimes & $19 \%(3)$ \\
\hline Rarely & $31 \%(5)$ \\
\hline \multirow{2}{*}{\multicolumn{2}{|c|}{ Weekly number of hives score }} \\
\hline & \\
\hline Most of the time & $13 \%(2)$ \\
\hline Sometimes & $25 \%(4)$ \\
\hline Rarely & $19 \%(3)$ \\
\hline Never & $44 \%(7)$ \\
\hline \multicolumn{2}{|l|}{ DLQI } \\
\hline Most of the time & $38 \%(6)$ \\
\hline Sometimes & $25 \%(4)$ \\
\hline Rarely & $25 \%(4)$ \\
\hline Never & $13 \%(2)$ \\
\hline \multicolumn{2}{|l|}{ CU-Q2oL } \\
\hline Sometimes & $25 \%(4)$ \\
\hline Rarely & $25 \%(4)$ \\
\hline Never & $50 \%(8)$ \\
\hline \multicolumn{2}{|l|}{$A E-Q o L$} \\
\hline Sometimes & $6 \%(1)$ \\
\hline Rarely & $31 \%(5)$ \\
\hline Never & $63 \%(10)$ \\
\hline \multicolumn{2}{|c|}{ Section 4: Use of guidelines and perceived barriers } \\
\hline \multicolumn{2}{|c|}{$\begin{array}{l}\text { Do you use guidelines to direct } \\
\text { your management of urticaria? }\end{array}$} \\
\hline Yes & $89 \%(17)$ \\
\hline No & $11 \%(2)$ \\
\hline \multicolumn{2}{|l|}{ Which guidelines do you refer to? } \\
\hline EACCI/GA(2)LEN/EDF/WAO & $50 \%(8)$ \\
\hline Other & $38 \%(6)$ \\
\hline Local guidelines & $13 \%(2)$ \\
\hline \multicolumn{2}{|l|}{ Support services for patients } \\
\hline Access to nursing support & $89 \%(16)$ \\
\hline Access to inpatient facilities & $61 \%(11)$ \\
\hline Dedicated urticaria service & $56 \%(10)$ \\
\hline Nurse prescribers & $28 \%(5)$ \\
\hline \multirow{2}{*}{\multicolumn{2}{|c|}{$\begin{array}{l}\text { Main perceived barriers to } \\
\text { prescribing systemic medications }\end{array}$}} \\
\hline & \\
\hline \multicolumn{2}{|l|}{ Cost } \\
\hline Side effects of treatments & \\
\hline Views expressed by patient & \\
\hline Long-term toxicity & \\
\hline
\end{tabular}

AE-QoL, Angioedema Quality of Life Questionnaire; CU-Q2oL, Chronic Urticaria Quality of Life Questionnaire EACCI/GA(2)LEN/ EDF/WAO, European Academy of Allergy and Clinical Immunology, Global Allergy and Asthma European Network. European Dermatology Forum and World Allergy Organization; DLQI, Dermatology Life Quality Index; UAS7, weekly Urticaria Activity Score.

Activity Score (UAS-7, 63\%), the Physician Global Assessment (63\%), the Patient Global Assessment (44\%) and the Dermatology Quality of Life Index (DLQI) (38\%). Guidelines are used by $89 \%$ to direct their management of CSU, with $50 \%$ using the EAACI/GA2LEN/EDF/WAO guideline, ${ }^{1}$ compared with $31 \%$ primarily using the BSACI guideline. ${ }^{2}$ The main perceived barriers to prescribing systemic medications were potential adverse effects (AEs) (32\% strongly agreed), potential long-term toxicity (26\% strongly agreed), cost of treatment ( $42 \%$ strongly agreed), and views expressed by the patient and their family (37\% agreed).

Our findings show variance between dermatology, allergy and immunology consultants with regard to the prescribing of systemic agents in CSU (Fig. 2). Our findings suggest that allergists are more likely to prescribe omalizumab as first-line treatment, whereas dermatologists more commonly prescribe ciclosporin, which is not in keeping with National Institute for Care Excellence guidance. ${ }^{3}$

Drug-related AEs are the main perceived barrier for clinicians to prescribe systemic medications. Other barriers to prescribing are the cost of medications. The list price for omalizumab $300 \mathrm{mg}$ monthly for 12 months is $£ 6150,{ }^{4}$ excluding the cost of post-injection observations required in a secondary care setting, whereas ciclosporin (in generic formulation) costs $£ 2660$ for 12 months (300 mg/day; $4 \mathrm{mg} / \mathrm{kg} /$ day for a patient weighing $75 \mathrm{~kg}){ }^{4}$ excluding the cost of renal function and blood-pressure monitoring. The main limitation to our survey was the number of respondents, as we chose to focus on consultant physicians with a specialist interest in urticaria.

In summary, our UK survey highlights the differences in management of CSU between dermatologists and other specialists, resulting in variation in the care provided for patients with CSU. Although national and international treatment guidelines now recommend omalizumab as a

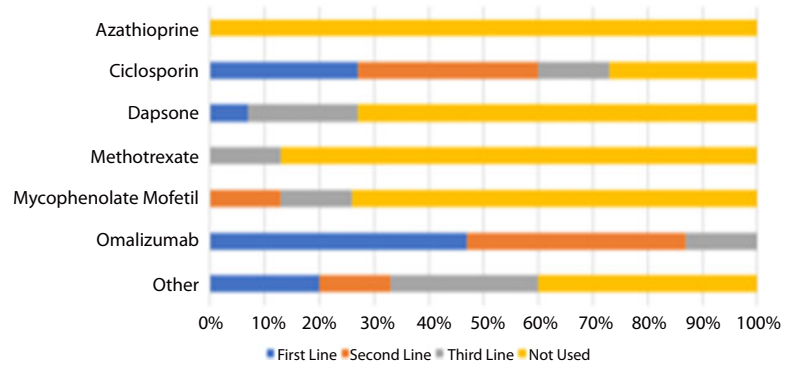

Figure 1 First-, second- and third-line systemic drug selection. 


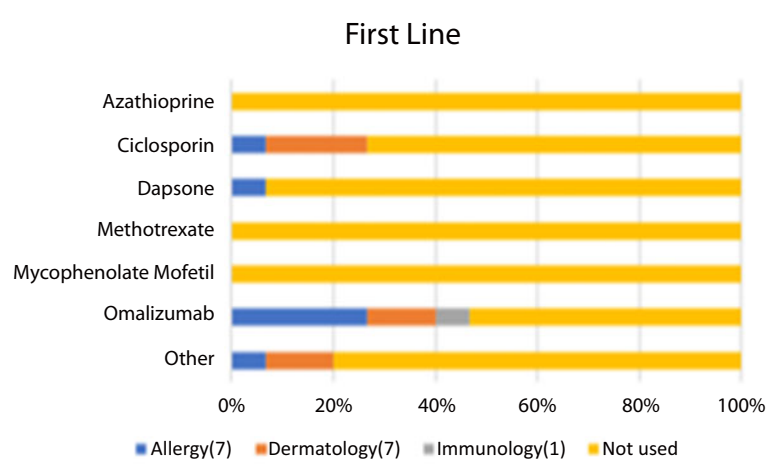

Second Line

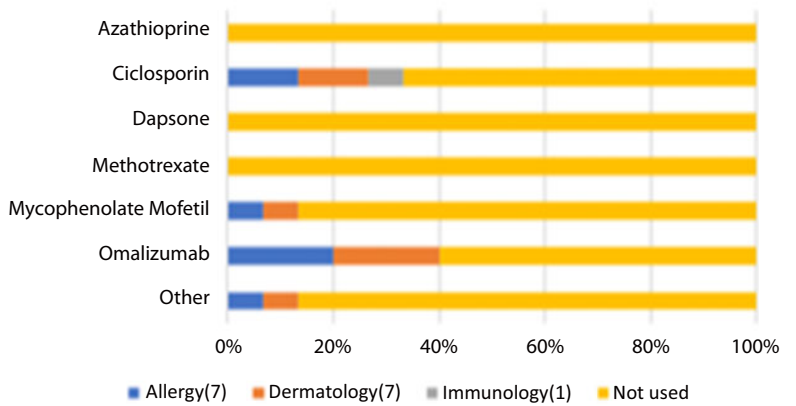

Third Line

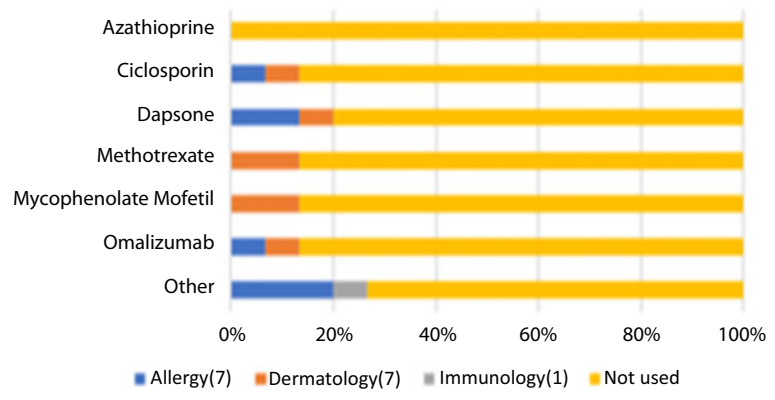

Figure 2 First-, second- and third-line systemic drug selection by specialty.

first-line agent for severe CSU not responding to antihistamine and montelukast treatment, these guidelines are based on placebo-controlled studies. The current lack of head-to-head comparisons between conventional systemic and biologic therapies may explain some of the variation in treatment approaches we observed, and highlights the need for further research in this area, including a comprehensive health economics evalation. ${ }^{3,5}$

\section{Acknowledgement}

The UK DCTN is grateful to the British Association of Dermatologists and the University of Nottingham for financial support of the Network.
B. Ho ${ }^{1}$, K. Heelan ${ }^{2}$, L. Solman ${ }^{3}$, R. Jones ${ }^{4}$, J. Dua ${ }^{5}$, J. R. Ingram ${ }^{6}$ (iD and C. Flohr ${ }^{7}$ iD

${ }^{1}$ Dermatology Department, St. George's Hospital, London, UK;

${ }^{2}$ Dermatology Department, Royal Marsden Hospital, Fulham Road, London, UK; ${ }^{3}$ Department of Paediatric Dermatology, Great Ormond Street Hospital for Children, London, UK; ${ }^{4}$ Dermatology Department, Edinburgh Royal Infirmary, Edinburgh, Scotland, UK; ${ }^{5}$ Dermatology Department, Royal Berkshire Hospital, Reading, UK; ${ }^{6}$ Division of Infection \& Immunity, Cardiff University,, Cardiff, Wales, UK; and

${ }^{7}$ Unit for Population-Based Dermatology Research, St John's Institute of Dermatology, Guy's and St Thomas, NHS Foundation Trust,

London, UK

E-mail: bernard.ho@stgeorges.nhs.uk

Conflict of interest: the authors declare that they have no conflicts of interest.

JRI and CF are on the editorial board of the British Journal of Dermatology, which is owned by the same society as Clinical and Experimental Dermatology.

Accepted for publication 25 April 2018

\section{References}

1 Zuberbier T, Aberer W, Asero R et al. The EAACI/GA\# LEN/EDF/WAO Guideline for the definition, classification, diagnosis, and management of urticaria: the 2013 revision and update. Allergy 2014; 69: 868-87.

2 Powell RJ, Leech SC, Till S et al. BSACI guideline for the management of chronic urticaria and angioedema. Clin Exp Allergy 2015; 45: 547-65.

3 National Institute for Health and Care Excellence. Omalizumab for previously treated chronic spontaneous urticaria. NICE Technology Appraisal Guidance (TA339), 2015. Available at: https://www.nice.org.uk/guidance/ta 339 (accessed 30 April 2018).

4 Joint Formulary Committee. British National Formulary. Available at: http://www.medicinescomplete.com (accessed on 10 January 2017).

5 Maurer M, Kaplan A, Rosén K et al. The XTEND-CIU study: long-term use of omalizumab in chronic idiopathic urticaria. J Allergy Clin Immunol 2018; 141(1138-9): e7. 